\title{
Post-containment management of nursing homes: a new public health concern
}

\author{
Denis Boucaud-Maitre $^{1}$ (D) $\cdot$ Roxane Villeneuve ${ }^{1} \cdot$ Maturin Tabue-Teguo $^{1,2}$
}

Received: 9 April 2020 / Accepted: 27 April 2020 / Published online: 13 May 2020

(c) European Geriatric Medicine Society 2020

As containment measures have just been implemented in India, nearly 3.4 billion people are now confined to their homes by governmental decree, due to the COVID-19 pandemic. While some countries have declared general containment (France, Italy, Spain), other countries (USA, China, Russia) have implemented partial containment. For the latter, only specific areas (cities, regions, provinces, etc.), or categories of the population (because of their age, in particular), are affected by these measures.

The aim of containment is to limit the spread of the virus, hence avoiding healthcare disorganization and the saturation of hospital intensive care units [1]. However, the length of containment required to achieve this objective may vary. In the Wuhan region (China), where no new cases of infection have been officially reported for a few days, at least 8 weeks of strict containment were necessary. This was the option chosen by Italy, Spain and France, who report the highest number of COVID-19 cases, and UK authorities do not rule out the possibility of at least partial containment for another 6 months. Unless the virus disappears on its own, other outbreaks may occur in the months to come: these heterogeneous containment measures may not be sufficient in a context of globalization and constant population migrations. Even after the pandemic ends, lifting containment for vulnerable elderly people will not be that easy.

There is no doubt that nursing home residents will experience longer periods of containment than the rest of the population. Right now, if nursing homes usually provide residents and their families with guaranties of safety and continuous care, nursing homes are the places where older people face the greatest risks once the virus has entered the

Denis Boucaud-Maitre

denis.boucaud@gmail.com

1 University Hospital of Guadeloupe, Route de Chauvel, 97159 Pointe-à-Pitre Cedex, Guadeloupe, France

2 Faculty of Medicine, University of the French West Indies, 97154 Pointe-à-Pitre, Guadeloupe, France premises. Indeed, older people with multiple comorbidities are particularly vulnerable to the virus [2], and the mortality rates of infected nursing home residents are considerable (more than 30\%) [3]. Immediate measures have already been implemented, such as visitation bans or restrictions, early identifications of infections, social distancing among residents or personal protective equipment for health workers [4]. Strict containment, while humanly unsustainable, remains the most adequate measure to prevent the disease from emptying nursing homes from their residents in a few weeks or months. This seems to call for a longer containment period in nursing homes than in the rest of the population. Nevertheless, in addition to the known deleterious consequences of prolonged containment (anxiety, depression, even Post-Traumatic Syndrome Disorder), that could especially be observed in nursing homes with the highest death tolls, this situation could have a long-term psychological impact on the residents, their families, and the staff, since it exposes the residents to lasting freedom deprivation, anxiety and social isolation, leading to higher all-cause mortality, a situation calling for a gradual lifting of containment measures as soon as possible.

Several questions thus need to be addressed: how long should containment last, how long should hygiene measures and social distancing be maintained after the virus has died out? Do we have adequate economic resources to ensure the protection of both the physical and psychosocial well-being of the residents?

In the current context, one measure that would allow the residents to maintain a visual contact and talk to their relatives would be to provide them with opportunities to make video calls. Nevertheless, not all nursing homes have the appropriate equipment, and not all residents can afford a smartphone and an internet connection. Initiatives from nursing home personnel to encourage social activities and ways of coping with the isolation are starting to emerge, but may prove to be difficult to maintain in the likely case of strict confinement to one's room. 
Once the epidemic starts dying out, visits could be authorized under strict conditions (distance, wearing masks, disposable gowns) and limited to those whose contact is essential to the confined person. Compassionate measures will also be essential for the residents and their families in the event of a sudden worsening of the residents' health.

We remain hopeful that simple tests for detecting COVID19 will soon be generalized. These tests would tell within a few minutes whether a visitor is or has been infected. Maintaining precautionary measures will remain essential as long as the sensitivity of these tests and the time it takes for them to detect positive cases are not known. Whether these expensive tests should be performed at each visit remains to be determined. These tests and strict hygiene measures should be, in our opinion, maintained even if the several ongoing clinical trials provide us with effective medicine or vaccines. Indeed, older people tend to be excluded from clinical trials, especially frail ones. In this context, it is important to prepare nursing homes psychologists to the aftermath. This should be done by providing those who need it with additional training, especially in the management of post-traumatic stress disorder symptoms.

In conclusion, post-containment management of nursing homes will require a combination of medical, psychological, political and economic resources. Until a proper management plan is drafted, nursing homes residents are in for a lonely journey.
Author contributions DBM and RV write the manuscript, MTT reviews the manuscript.

\section{Compliance with ethical standards}

Conflict of interest The authors declare that they have no competing interest

Ethical approval Not applicable.

Informed consent Not applicable.

\section{References}

1. Flaxman, S, Mishra, S, Gandy, A et al (2020 Estimating the number of infections and the impact of non-pharmaceutical interventions on COVID-19 in 11 European countries. Imperial College London. https://doi.org/10.25561/77731

2. Huang C, Wang Y, Li X et al (2020) Clinical features of patients infected with 2019 novel coronavirus in Wuhan China. Lancet 395(10223):497-506. https://doi.org/10.1016/S0140 $-6736(20) 30183-5$

3. McMichael TM et al (2020) Epidemiology of Covid-19 in a longterm care facility in King County Washington. N Engl J Med. https://doi.org/10.1056/NEJMoa2005412

4. Center for Disease Control and Prevention. Key Strategies to Prepare for COVID-19 in Long-term Care Facilities (LTCFs), 2020. https://www.cdc.gov/coronavirus/2019-ncov/hcp/long-term-carestrategies.html

Publisher's Note Springer Nature remains neutral with regard to jurisdictional claims in published maps and institutional affiliations. 